\title{
Digitalis: where are we now?
}

\author{
D A CHAMBERLAIN
}

From the Royal Sussex County Hospital, Brighton

... Time will fix the real value on this discovery, and determine whether I have imposed upon myself and others, or contributed to the benefit of science and mankind.

\section{William Withering ${ }^{1}$}

Digitalis can still arouse controversy and even passion, but none can deny that it has passed the test of time perceived by Withering as a prime marker of value. Few opportunities will ever arise to celebrate the bicentenary of a drug, for what others will last the course? But digitalis has not done so with an untarnished reputation-problems have been apparent from the outset. Withering himself was concerned that digitalis might "be regarded as dangerous and unmanageable" if his advice on usage went unheeded.

This early warning on the hazards of digitalis toxicity received less attention than it merited, though the picture became clear only with hindsight. Even now we cannot know how the balance would look if the accrued benefit of 200 years could be weighed against the unintended harm. Major advances in the pharmacodynamics and pharmacokinetics of the drug in the past two decades now mean that science can replace empiricism. Now (with new knowledge combined with old but valid precepts) we should be able to use digitalis more judiciously, more safely, to better effect, but perhaps less widely than in the past. Withering would be content with that.

\section{The actions of digitalis}

Digitalis is a drug with an unlikely profile. It stimulates the myocardium while depressing sinoatrial and particularly atrioventricular nodal function; these apparently disparate actions match exquisitely the

Requests for reprints to Dr D A Chamberlain, Royal Sussex County Hospital, Eastern Road, Brighton, Sussex BN2 5BE. requirements for treating patients with atrial fibrillation and heart failure.

The mechanisms by which these effects are achieved are complex, but at cellular level they relate principally to inhibition of sodium-potassium adenosine triphosphatase. ${ }^{2}$ Some adenosine triphosphatase related effects, notably those on contractility, are mediated directly by changes in ionic concentrations across cell membranes. Others, principally the electrical ones, follow more from modulation of the autonomic system. Increased vagal activity and the sensitivity of the sinoatrial and atrioventricular nodes to such activity are most important-sympathetic influences are reduced at therapeutic doses and increased when toxic concentrations are reached. ${ }^{3}$ The nodes have little direct response, as can be demonstrated by modest or inconsistent changes after transplantation ${ }^{4}$ or pharmacological blockade. ${ }^{5}$ Some of the therapeutic effects of digitalis in heart failure depend also upon changes in peripheral venomotor tone. ${ }^{6}$

\section{Commonly used cardiac glycosides}

Digitalis leaf in the tablet form is now of mainly historical interest. Digitoxin, ouabain, digoxin, medigoxin, and lanatoside $C$ are the preparations used in Britain to greater or lesser degree. They have widely disparate pharmacokinetics. Not all the differences are sufficiently recognised, though they have been well described in authoritative reviews. ${ }^{7}$

Digitoxin is the most important constituent of Digitalis purpurea. In its modern purified form it deserves a more prominent role among the cardiac glycosides. Digitoxin is rapidly and fully absorbed after oral administration. Over $90 \%$ of the glycoside present in plasma is bound to albumin but only the free fraction exchanges readily with tissue sites. The ratio of myocardial to plasma concentration is less than 10:1. Metabolism is important, since at least $50 \%$ of administered digitoxin undergoes transformation in the liver; some of the resulting com- 
pounds retain cardioactivity. Digitoxin and most of its metabolites are excreted in the bile, but the parent compound is absorbed again in the enterohepatic cycle.This and the avid protein binding that permits only limited renal excretion account for the relatively long plasma half life-nearly five days even with normal hepatic function. Loss in the faeces and urinary excretion both of digitoxin and its metabolites ultimately account for elimination.

Ouabain (strophanthin G) is found in Strophanus gratus and is a glycoside related to digitalis. Gastrointestinal absorption is poor and unreliable; administration must therefore be intravenous. Haemodynamic effects occur more rapidly than with digoxin and peak effects are obtained within two hours. Elimination is also faster (plasma half life of about 18 hours) and mostly renal, though the drug is also lost through the gut.

Digoxin is obtained from Digitalis lanata. It is incompletely absorbed; on average about $70 \%$ enters the circulation. In the past, tablet brands and even batches differed widely in the bioavailability of their digoxin content. Changes in manufacture of Lanoxin in 1969 and 1972, leading first to a reduction in bioavailability and then to an increase, ${ }^{8}$ prompted an appraisal of the variation between brands. Such differences were of considerable clinical importance ${ }^{9}$ and potentially dangerous ${ }^{10}$ yet had remained unknown until that time. A new standard for dissolution rate has led to acceptable uniformity and much greater safety. Differences in capacity for absorption between individuals are usually slight. Though the process is susceptible to interference (see below), timing of dosage in relation to meals makes only a small difference. About $10 \%$ of digoxin in plasma is protein bound. The ratio of myocardial to plasma concentration is approximately 100:1. Digoxin is not metabolised after absorption. But metabolism by micro-organisms may occur within the bowel after ingestion. ${ }^{11}$ Eubacterium lentum, an anaerobic saprophyte, can inactivate digoxin by reduction of the lactone ring of the molecule and is responsible for the apparent resistance to the effects of the drug in a minority of individuals. The potential for drug toxicity is increased in subjects harbouring this organism since abrupt changes in gut flora, such as occur with antibiotic treatment, may restore the full potential for glycoside absorption. Digoxin is eliminated principally by the kidney. The key role of renal function in the rate of elimination of digoxin became clear when the pharmacokinetics of tritiated digoxin were investigated. ${ }^{12}$ Toxicity must have been very common in patients with impaired renal function before this important fact was recognised. Even now some hazard remains, since many patients are given empirical doses of the glycoside when the state of their renal function is quite unknown.

Medigoxin is beta-methyl digoxin. This preparation is absorbed more readily than digoxin and is subsequently converted to it. Though better absorption implies less variation in bioavailability, the drug has not found wide favour in Britain.

Lanatoside $C$ is obtained from Digitalis lanata. Absorption is poorer than that of digoxin; conversion to digoxin occurs, mainly in the gut. ${ }^{13}$ Intolerance to digoxin is therefore not a rationale for using this glycoside. Variation in bioavailability must be greater than with digoxin, in keeping with the principle that the poorer the absorption of a drug the greater the potential for variation.

\section{Do glycosides improve heart failure?}

No physician will dispute the value of cardiac glycosides in slowing the ventricular rate of patients with atrial fibrillation and preventing many instances of supraventricular tachycardia. These arrhythmias may promote or exacerbate heart failure and in such cases digoxin may have an important controlling effect.

The value of digitalis in heart failure with sinus rhythm is more contentious. Most of the evidence for an important inotropic effect relates to the acute heart failure. Early experimental observations ${ }^{1415}$ were followed by clinical measurements of increased contractility; one of the most convincing was based on force velocity curves obtained by means of radioopaque markers sewn on to the myocardium at operation. ${ }^{16}$ Shifts in these curves with ouabain treatment indicated a positive inotropic effect but some were associated with slight falls in cardiac output. These falls are now known to depend on reflex adjustments of venous return and peripheral resistance but they have been incorrectly interpreted as denying the possibility of clinical benefit. Noninvasive measurements of systolic time intervals confirm a positive inotropic action both for subjects with normal hearts ${ }^{17}$ and those with heart failure. ${ }^{18}$ Though favourable changes in cardiac output are not found at rest, differences may be observed during exercise. ${ }^{19}$ The paucity of exercise data reflects the greater difficulty in making meaningful observations in a complex system replete with possibilities for autoregulation. Overall, the balance of evidence rests heavily in favour of digitalis augmenting contractility acutely, both in the presence of normal ventricular function and in heart failure.

The evidence for a persistence of benefit in chronic heart failure should be examined separately from that relevant to acute failure. Data from the latter are often extrapolated to chronic heart failure, 
but the notion has rarely been addressed; indeed clinical and laboratory experiments to prove or refute it are difficult to devise. Some information on duration of effect is available, however. An ingenious method of assessing an index of contractility was described by Davidson and Gibson. ${ }^{20}$ The acceleration of the ball inside the Starr-Edwards valve can be measured non-invasively; by this technique the augmented power of contraction after acute digitalisation diminished rapidly after only a few hours. On the other hand Griffiths and colleagues adduced evidence from studies with $M$ mode echocardiography and systolic time intervals that the inotropic effects of digoxin had diminished six weeks after long term maintenance digoxin had been discontinued compared with observations made during treatment. ${ }^{21}$ Arnold and colleagues drew similar conclusions from haemodynamic measurements. ${ }^{22}$ An index of heart failure based on a complex combination of clinical and radiographic observations was also lowered by digoxin in a placebo controlled trial. ${ }^{23}$ Even if digitalis does exert a continuing positive inotropic effect during sustained use, the action may not be apparent subjectively. Several studies attest to the lack of any observable deleterious effect when the drug is discontinued. ${ }^{2425}$ But subtle changes of importance during exercise or in maintaining compensation under critical conditions could easily be missed by simple clinical observations. In summary, we do not know whether cardiac glycosides can exert a useful sustained effect in the treatment of chronic heart failure.

\section{Measurements of plasma concentrations of digoxin and digitoxin}

For most of the 200 years that digitalis has been in common use its clinical pharmacology was poorly understood because plasma and tissue concentrations could not be measured. But once isotopically labelled glycoside became available rapid progress was made in pharmacokinetic studies, and the crucial importance of renal function in digoxin therapy became apparent.

Reliable measurements in patients on maintenance therapy followed the introduction of radioimmunoassay in $1969 .{ }^{26}$ Most therapeutic concentrations of digoxin are in the range 1-2 $\mu \mathrm{g} / 1$ (1.28-2.56 $\mu \mathrm{mol} / 1)$, but lower concentrations will suffice if, for example, atrioventricular nodal function is already impaired so that only a small additional effect is needed to control heart rate satisfactorily. Concentrations of digitoxin tend to be 10 to 15 times higher because of the greater protein binding of the drug. Samples for both assays are best taken when plasma concentrations have reached a relatively steady state after drug ingestion, that is about six to eight hours after the last dose. After this results may be misleadingly low.

Measurements of plasma concentrations are not needed in most patients on maintenance therapy. Certainly they do not automatically provide an answer for achieving an optimal dose since complex relations between the drug, the state of the cardiac tissues, and the many metabolic and therapeutic interactions at cellular level all combine to create a wide range of possible therapeutic concentrations within which only a narrow band may be appropriate for one individual or for one individual at a given time. Even the newly available rapid plasma digoxin assay should not replace careful chemical monitoring for dose selection in the majority of patients. ${ }^{27}$ But measurements may be useful as a guide to the diagnosis of toxicity and in investigating apparent failures of response (especially when unusually large doses of glycoside are administered). Assays are of great value in pharmacokinetic research.

Other limitations of plasma concentrations must be recognised. Carelessness in defining the interval between dose and sampling can cause misleading results. Spurious values have been reported as a result of cross reactions from an antibody of unsatisfactory specificity in the presence of other drugs $^{28}$ and from cross reactions from unknown substances in patients with liver disease, ${ }^{29}$ renal impairment, ${ }^{30}$ and in premature infants. ${ }^{31}$

\section{Unwanted effects and toxicity of digitalis}

Efficacy is not the sole consideration when judging the value of a drug; beneficial effect must always be balanced against toxicity and unwanted effects. The load of adverse effects with digitalis is weighty; toxicity is common even during use by skilled and cautious physicians. The reasons are manifold. First, the differences in plasma or tissue concentrations associated with optimal beneficial effect or with toxicity are small; they may even overlap. ${ }^{32}$ Secondly, variations in absorption, metabolism, or excretion of glycosides cannot readily be assessed; thus the precision with which plasma concentrations can be predicted is unsatisfactory. Thirdly, individuals show appreciable variation in the sensitivity of some tissue responses to cardiac glycosides; a plasma level inadequate for one patient may be excessive for another. This is true for example, of conductivity within the atrioventricular node. ${ }^{32}$ Finally, abrupt changes in response can occur as a result of drug interactions.

With this catalogue of problems, unwanted effects must be frequent. Hurwitz and Wade drew attention to the problem in 1969 when they found $20 \%$ of patients on maintenance therapy had unwanted 
effects. ${ }^{33}$ This could have been ascribed to the carelessness of outpatient prescribing, but in 1971 Evered and Chapman made similar observations on patients in a British hospital ${ }^{34}$ as did Beller and colleagues in an American one ${ }^{35}$; these later studies were supported by newly available assays for plasma glycoside concentration. Perhaps significantly, a study of patients treated exclusively with digitoxin showed only a $5 \%$ prevalence of toxicity. ${ }^{36}$ Absorption and elimination of this glycoside are relatively consistent; since plasma concentrations must be more predictable, digitoxin may perhaps be safer than digoxin, though it would be difficult to prove this assertion.

The clinical manifestations of digitalis toxicity are believed to depend on two interacting mechanisms. The first is related to the effect of plasma concentrations on the central nervous system, and includes not only the familiar side effects of nausea, vomiting, and altered vision but also those cardiac effects due to increased vagal tone. These tend to be very distressing but rarely dangerous. The second mechanism depends on tissue concentration and is related to the increased automaticity of subsidiary cardiac pacemakers and arrhythmias triggered by micro reentry. These are potentially more serious and even life-threatening.

There is considerable variation in the plasma and tissue concentrations at which toxicity occurs because of differences between patients in sensitivity and vulnerability of the myocardium, the conducting system, and other tissues. For digoxin, serious manifestations of toxicity are unusual with plasma concentrations below $2 \mu \mathrm{g} / 1(2.56 \mu \mathrm{mol} / \mathrm{l})$ but are likely to be present with concentrations over $3 \mu \mathrm{g} / 1$ (3.84 $\mu \mathrm{mol} / \mathrm{l}){ }^{35}$ Between these figures some patients have a satisfactory therapeutic response while others show evidence of serious toxicity.

The extracardiac manifestations of digitalis toxicity were studied after a manufacturing accident in Holland $^{37}$ : digitoxin was inadvertently substituted for digoxin and therefore administered to a community in excessive dosage. Fatigue and profound muscular weakness were almost invariable. These are very non-specific symptoms, readily ascribed to the underlying disease, the effects of inactivity, or even imagination. We now know that they deserve closer attention in patients treated with glycosides. Other symptoms in the Dutch study included the expected visual and gastrointestinal disturbances, together with headache, restlessness, and agitation. Muscular cramps have also been reported. ${ }^{38}$

In the absence of myocardial disease the cardiac manifestations of high plasma concentrations of cardiac glycosides are relatively benign. Though first, second, and third degree atrioventricular blocks occur, prolonged pauses are infrequent because the $\frac{C}{.}$ automaticity of subsidiary pacemakers in enhanced. $\overrightarrow{\vec{F}}$ In patients with heart disease the manifestations are ? more complex and more serious. The association of $\frac{}{0}$ tachycardias with atrioventricular block is character $-\frac{\bar{v}}{\bar{N}}$ istic; frequent ventricular extrasystoles, ventricular $\vec{\widehat{ }}$ tachycardia, and venticular fibrillation are well rec- $\propto$ ognised, but some digitalis arrhythmias are very difficult to characterise.

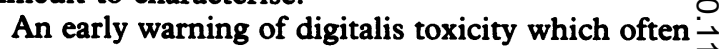
passes unheeded is progressive regularisation of the $\vec{\omega}$ ventricular response in atrial fibrillation. ${ }^{39}$ The phy- $\frac{\rho}{\partial}$ sician should make a habit of deciding whether or not the heart rate with atrial fibrillation is as "irregularly irregular" as his teachers had him believe.

Very high plasma concentrations of digitalis may be associated with severe hyperkalaemia and ${ }_{0}$ asystole. This cannot be treated successfully by con- $工$ ventional methods, though the use of specific anti- $\vec{c}$ body fragments will have a role in the severest forms $\frac{\mathbb{}}{0}$ of intoxication if such treatment becomes com- $\stackrel{\mathbb{\Phi}}{\mathbb{D}}$ ercially available. ${ }^{40}$

Some authorities consider that digitalis should be $\stackrel{\Phi}{\frac{\Phi}{7}}$ used with particular caution in patients with severe $\overrightarrow{0}$ ischaemic heart disease because the threshold to ven- of tricular fibrillation may be lowered in this group which is already at high risk from sudden death. Moss and colleagues demonstrated that patients treated with digitalis were more likely to die suddenly than others not so treated. ${ }^{41}$ Three other studies have implicated digitalis as an independent risk $\stackrel{\varnothing}{\circ}$ factor after infarction, though the Coronary Artery $\overrightarrow{\overrightarrow{0}}$ Surgery Study did not. ${ }^{42}$ Adequately controlled 3 trials cannot readily be conducted and a misleading impression may be obtained if patients with more severe disease tend to receive treatment with gly- $\vec{\nabla}$ cosides. For the moment the verdict on this point $\stackrel{D}{7}$ must be "under suspicion but not proven".

\section{Drug interactions}

The interactions of digoxin and digitoxin with other agents have been described in over 400 papers listed in Index Medicus since 1980, and in very many more over the previous decade. The wise physician should hesitate before prescribing a glycoside with any of other drug. This is indeed serious advice since digi- N talis has a perilously low therapeutic ratio.

Interactions can occur because of induced variations in absorption, or metabolism, or excretion in urine or bile; variations in protein or tissue binding, $\overparen{\Phi}$ because of changes in adenosine triphosphatase $\stackrel{\oplus}{-}$ activity, and because of additive or competitive 7 effects on cardiac tissues. Many interactions involve $\vec{D}$ more than one mechanism, some have not been fully elucidated, and doubtless many remain unknown. 
The absorption of digoxin from the gut is incomplete and therefore variable. Agents such as propantheline that slow transit time through the bowel will increase digoxin absorption while agents such as metoclopramide that speed emptying will decrease it. ${ }^{43}$ Resins such as cholestyramine ${ }^{44}$ and even simple antacids ${ }^{45}$ will readily adsorb digoxin and retain it within the gut lumen. Are house officers aware of this when antacids are given on demand to patients with atrial fibrillation? Digitoxin, which is usually completely absorbed, is less vulnerable, but cholestyramine and antacids also influence absorption of this glycoside.

Microsomal enzymes which are responsible in part for the hepatic metabolism of digitoxin are inducible by phenobarbitone and phenytoin. Plasma concentrations of the glycoside can therefore be reduced by these drugs. ${ }^{46}$ Digoxin is metabolised within the gut by Eubacterium lentum in some individuals. ${ }^{11}$ Hence, agents such as antibiotics that alter gut flora may have profound effects on the bioavailability of digoxin.

The excretion of digitoxin in bile and its enterohepatic cycle are subject to interference. Cholestyramine can bind the glycoside and prevent reabsorption. This effect can be used to counteract digitoxin toxicity, since the plasma half life can be markedly reduced with the resin. ${ }^{47}$ The renal excretion of digoxin is partly by glomerular filtration and partly by tubular excretion. ${ }^{48}$ The latter is susceptible to interference by triamterene and spironolactone. Increases in plasma concentrations are relatively small. Moreover, canrenoate (a metabolite of spironolactone) probably competes for myocardial binding sites $^{49}$; thus higher plasma concentrations may not be reflected by higher tissue concentration.

Drugs known to be albumin bound, such as sulphonamides, phenobarbitone, and tolbutamide, displace digitoxin and change the ratio of free to bound drug within the plasma. But the effects are small and of only minor clinical importance. ${ }^{46}$

The mechanisms of some important interactions are not completely understood, partly because they are complex. Quinidine, for example, may influence absorption, excretion, and apparent volume of distribution of digoxin. ${ }^{\text {so }}$ Plasma concentrations are increased but displacement from myocardial receptors has been postulated. Verapamil, ${ }^{51}$ amiodarone, ${ }^{52}$ nifedipine, ${ }^{53}$ and ibuprofen ${ }^{54}$ are also among common drugs that increase plasma digoxin concentrations. Symptoms arising within the central nervous system are exacerbated, but serious toxicity may depend more on whether tissue concentrations are increased or decreased; evidence on this point is sparse. Rifampicin decreases plasma concentrations of glycosides, especially of digitoxin. ${ }^{55}$
The plasma potassium concentration influences digitalis effects by affecting sodium-potassium adenosine triphosphatase. ${ }^{56}$ Most clinicians recognise the peril of hypokalaemia from diuretics used in heart failure, which is usually exacerbated by high aldosterone levels. Less well recognised is the rapid and often profound hypokalaemia mediated by beta ${ }_{2}$ receptors as a result of intense sympathetic stimulation. ${ }^{57}$ How far the danger of this is exacerbated by concomitant treatment with glycosides and how far treatment with non-selective beta blockers can be protective remain speculative.

Competing or additive inotropic and chronotropic effects from other cardioactive drugs merit litte comment. The concept of an inotropic ceiling may be worthy of mention, however. This refers to the inotropic reserve that exists even in the failing heart. It is not clear whether the ceiling of augmentation can be reached by inotropic drugs, ${ }^{58}$ but additive effects are unlikely. Thus there may be little point in using digitalis for acute heart failure if more powerful agents such as catecholamines are given concurrently. Cardiac glycosides may have a role, however, during the difficult withdrawal of catecholamines when there is down regulation ${ }^{59}$ of beta receptors.

\section{Digitalis: where are we now?}

The cardiac glycosides are difficult and dangerous drugs and they are used in vulnerable patients. We would abandon them if we had effective substitutes. The introduction of better diuretics, vasodilators, and perhaps alternative oral inotropic agents ${ }^{60}$ has reduced the role of digitalis for the long term management of heart failure but we still require the agent that Withering gave us 200 years ago. We need it for the control of atrial fibrillation in many patients, for treatment and prophylaxis of supraventricular tachycardias in a few, for acute left ventricular failure in most, and for chronic heart failure when other options seem inadequate. Perhaps digitoxin with its more predictable absorption and elimination and more constant plasma concentrations deserves more emphasis, and perhaps the rapid action of ouabain is insufficiently exploited.

Digitalis in its varying forms still has an important role and we cannot do without it. But each time a glycoside is prescribed the clinician should ask whether it is worth the risk of unwanted effects, will it suit the need better than other drugs, and how closely should the patient be supervised. We must not use digitalis needlessly nor unthinkingly. Where are we now? With the benefit of our new knowledge we are in a better position than ever before to use digitalis with the assurance that benefit should outweigh harm. Let those who have not done so take 
time to read Withering's treatise which still has much useful advice to offer.

The use of the Foxglove is getting abroad, and it is better that the world should derive some instruction, however imperfect, from my experience than that the lives of men should be hazarded by its unguarded exhibition or that a medicine of so much efficacy should be condemned and rejected as dangerous and unmanageable. ${ }^{1}$

\section{References}

1 Withering W. An account of the foxglove, and some of its medical uses: with practical remarks on dropsy, and other diseases. London: GGJ and J Robinson, 1785: $\mathrm{X}$ and V.

2 Schwartz A, Allen JC, Harigaya S. Possible involvement of cardiac $\mathrm{Na}^{+}, \mathrm{K}^{+}$-adenosine triphosphatase in the mechanism of action of cardiac glycosides. I Pharmacol Exp Ther 1969; 168: 31-41.

3 Gillis RA, Raines A, Sohn YJ, Levitt B, Standaert G. Neuroexcitatory effects of digitalis and their role in the development of cardiac arrhythmias. I Pharmacol Exp Ther 1972; 183: 154-68.

4 Goodman DJ, Rossen RM, Cannom DS, Rider AK, Harrison DC. Effects of digoxin on atrioventricular conduction. Studies in patients with and without cardiac autonomic innervation. Circulation 1975; 51: 251-62.

5 Alboni P, Shantha N, Filippi L, et al. Clinical effects of digoxin on sinus node and atrioventricular node function after pharmacologic autonomic blockade. Am Heart f 1984; 108: 1255-61.

6 Mason DT, Braunwald E. Studies on digitalis. X. Effects of ouabain on forearm vascular resistance and venous tone in normal subjects and in patients in heart failure. $\mathcal{F}$ Clin Invest 1964; 43: 532-43.

7 Smith TW, Haber E. Digitalis (third of four parts). $N$ Engl f Med 1973; 289: 1063-72.

8 Anonymous. Digoxin - warning. Addendum to Prescribers fournal 1972; 12: 100.

9 Lindenbaum J, Mellow MH, Blackstone MO, Butler VP Jr. Variation in biologic availability of digoxin from four preparations. $N$ Engl $\mathcal{F}$ Med 1971; 285: 1344-7.

10 Tunstall-Pedoe $\mathrm{H}$. Changing digoxin potency and cardiac mortality in England and Wales 1968-76. Br Heart f 1985; 54: 243-7.

11 Dobkin JF, Saha JR, Butler VP Jr, Neu HC, Lindenbaum J. Digoxin-inactivating bacteria: identification in human gut flora. Science 1983; 220: 325-7.

12 Doherty JE, Perkins WH, Wilson MC. Studies with tritiated digoxin in renal failure. $A m \mathcal{F}$ Med 1964; 37: 536-44.

13 Beermann B. Pharmaco-kinetics of lanatoside $C$ and methyldigoxin. In: Storstein D, ed. Symposium on digitalis. Oslo: Glydendal Norsk Forlag, 1973: 404-9.

14 Wiggers CJ, Stimson B. Studies on the cardiodynamic actions of drugs, III. The mechanism of cardiac stimu- lation by digitalis and g-strophanthin. $f$ Pharmacol Exp Ther 1927; 30: 251-69.

15 Cattell $M$, Gold $H$. The influence of digitalis glycosides on the the force of contraction of mammalian cardiac muscle. F Pharmacol Exp Ther 1938; 62: 116-25.

16 Sonnenblick EH, Williams JF Jr, Glick G, Mason DT, Braunwald E. Studies on digitalis. XV. Effects of car- $Q$ diac glycosides on myocardial force-velocity relations in the non-failing human heart. Circulation 1966; 34: 532-9.

17 Weissler AM, Gamel WG, Grode HE, Cohen S, $\overrightarrow{\vec{H}}$ Schoenfeld CD. The effect of digitalis on ventricular $\omega$ ejection in normal human subjects. Circulation 1964; 29: 721-9.

18 Weissler AM, Schoenfeld CD. Effect of digitalis on $\rightarrow$ systolic time intervals in heart failure. $\mathrm{Am} \mathcal{F}$ Med Sci $\omega$ 1970; 259: 4-20.

19 Murray RG, Tweddel AC, Martin W, Pearson D, Hutton I, Lawrie TDV. Evaluation of digitalis in cardiac 윽 failure. Br Med F 1982; 284: 1526-8.

20 Davidson C, Gibson D. Clinical significance of positive $C$ inotropic action of digoxin in patients with left ventric- $\frac{8}{8}$ ular disease. Br Heart $\mathcal{F}$ 1973; 35: 970-6.

21 Griffiths BE, Penny WJ, Lewis MJ, Henderson AH. Maintenance of the inotropic effect of digoxin on long- $\stackrel{\Phi}{-}$ term treatment. $\mathrm{Br} \mathrm{Med} \mathcal{F}$ 1982; 284: 1819-22.

22 Arnold SB, Byrd RC, Meister W, et al. Long-term digitalis therapy improves left ventricular function in heart failure. $N$ Engl f Med 1980; 303: 1443-8.

23 Lee DC, Johnson RA, Bingham JB, et al. Heart failure in outpatients. A randomized trial of digoxin versus placebo. N Engl f Med 1982; 306: 699-705.

24 Hull SM, Mackintosh A. Discontinuation of maintenance digoxin therapy in general practice. Lancet 1977; ii: $1054-5$.

25 Gheorghiade M, Beller GA. Effects of discontinuing maintenance digoxin therapy in patients with ischemic heart disease and congestive heart failure in sinus rhythm. Am F Cardiol 1983; 51: 1243-50.

26 Smith TW, Butler VP Jr, Haber E. Determination of therapeutic and toxic serum digoxin concentrations by radioimmunoassay. $N$ Engl $\mathcal{F}$ Med 1969; 281: 1212-6.

27 Savill J, Mitchell M, Wood D, Krikler DM. Rapid plasma digoxin assay in outpatients-a useful routine technique? Br Heart $\mathcal{F}$ 1985; 54: 348-50.

28 Bertler $\AA$, Redfors $A$. The ${ }^{86} \mathrm{Rb}$ method for digoxin assay. Comparison with radioimmunoassay. In: Storstein $\mathrm{O}$, ed. Symposium on digitalis Oslo: Glydendal Norsk Forlag, 1973: 64-70.

29 Nanji AA, Greenway DC. Falsely raised plasma N digoxin concentrations in liver disease. $\mathrm{Br} M e d ~ \mathcal{F} 1985$; 290: 432-3.

30 Graves SW, Brown B, Valdes R. An endogenous $\underset{\omega}{N}$ digoxin-like substance in patients with renal $O$ impairment. Ann Intern Med 1983; 99: 604-8.

31 Pudek MR, Seccombe DW, Whitfield MF, Ling E. Digoxin-like immunoreactivity in premature and full- $\stackrel{\mathcal{S}}{\rightarrow}$ term infants not receiving digoxin therapy. $N$ Engl $\mathcal{F}$ Med 1983; 308: 904-5.

32 Chamberlain DA, White RJ, Howard MR, Smith TW. Plasma digoxin concentrations in patients with atrial fibrillation. $\mathrm{Br}$ Med f 1970; iii: 429-32. 
33 Hurwitz N, Wade OL. Intensive hospital monitoring of adverse reactions to drugs. $\mathrm{Br} \mathrm{Med} \mathcal{F} 1969$; i: 531-6.

34 Evered DC, Chapman C. Plasma digoxin concentrations and digoxin toxicity in hospital patients. $\mathrm{Br}$ Heart $\mathcal{F}$ 1971; 33: 540-5.

35 Beller GA, Smith TW, Abelmann WH, Haber E, Hood WB Jr. Digitalis intoxication. A prospective clinical study with serum level correlations. $N$ Engl $\mathcal{Y}$ Med 1971; 284: 989-97.

36 Hillestad L, Hansteen V, Hatle L, Storstein L, Storstein O. Digitalis intoxication. In: Storstein O, ed. Symposium on digitalis. Oslo: Glydenal Norsk Forlag, 1973: 281-7.

37 Lely AH, van Enter CHJ. Large-scale digitoxin intoxication. Br Med f 1970; iii: 737-40.

38 Batterman RC, Gutner LB. Hitherto undescribed neurological manifestations of digitalis toxicity. Am Heart f 1948; 36: 582-6.

39 Kastor JA, Yurchak PM. Recognition of digitalis intoxication in the presence of atrial fibrillation. Ann Intern Med 1967; 67: 1045-54.

40 Smith TW, Haber E, Yeatman L, Butler VP Jr. Reversal of advanced digoxin intoxication with Fab fragments of digoxin-specific antibodies. $N$ Engl $\mathcal{F}$ Med 1976; 294: 797-800.

41 Moss AJ, Davis HT, Conard DL, DeCamilla JJ, Odoroff CL. Digitalis-associated cardiac mortality after myocardial infarction. Circulation 1981; 64: 1150-6.

42 Ryan TJ, Bailey KR, McCabe CH, et al. The effects of digitalis on survival in high risk patients with coronary artery disease. The Coronary Artery Surgery Study (CASS). Circulation 1983; 67: 735-42.

43 Manninen V, Apajalahti A, Melin J, Karesoja M. Altered absorption of digoxin in patients given propantheline and metoclopramide. Lancet 1973; i: 398-400.

44 Goldfinger SE, Heizer WD, Smith TW. Malabsorption of digoxin in malabsorption syndromes [Abstract]. Gastroenterology 1970; 58: 952.

45 Brown DD, Juhl RP. Decreased bioavailability of digoxin due to antacids and kaolin-pectin. $N$ Engl $\mathcal{F} M e d$ 1976; 295: 1034-7.

46 Solomon HM, Abrams WB. Interactions between digi- toxin and other drugs in man. Am Heart $₹$ 1972; 83: 277-80.

47 Caldwell JH, Greenberger NJ. Interruption of the enterohepatic circulation of digitoxin by cholestyramine. I. Protection against lethal digitoxin intoxication. I Clin Invest 1971; 50: 2626-37.

48 Steiness E. Renal tubular secretion of digoxin. Circulation 1974; 50: 103-7.

49 deGuzman NT, Yeh BK. Potassium canrenoate in the treatment of long-term digoxin-induced arrhythmias in conscious dogs. Am f Cardiol 1975; 35: 413-20.

50 Bussey HI. Update on the influence of quinidine and other agents on digitalis glycosides. Am Heart $\mathcal{F} 1984$; 107: 143-6.

51 Klein HO, Lang R, Weiss E, et al. The influence of verapamil on serum digoxin concentration. Circulation 1982; 65: 998-1003.

52 Moysey JO, Jaggarao NSV, Grundy EN, Chamberlain DA. Amiodarone increases plasma digoxin concentrations. Br Med F 1981; 282: 272.

53 Belz GG, Aust PE, Munkes R. Digoxin plasma concentrations and nifedipine [Letter]. Lancet 1981; i: 844-5.

54 Quattrocchi FP, Robinson JD, Curry RW Jr, Grieco ML, Schulman SG. The effect of ibuprofen on serum digoxin concentrations. Drug Intell Clin Pharm 1983; 17: 286-8.

55 Zilly W, Breimer DD, Richter E. Pharmacokinetic interactions with rifampicin. Clin Pharmacokinet 1977; 2: 61-70.

56 Akera T, Brody TM. The role of $\mathrm{Na}^{+}, \mathrm{K}^{+}-\mathrm{ATPase}$ in the inotropic action of digitalis. Pharmacol Rev 1978; 29: 187-220.

57 Brown MJ, Brown DC, Murphy MB. Hypokalemia from beta 2-receptor stimulation by circulating epinephrine. N Engl f Med 1983; 309: 1414-9.

58 Ross J. Mechanisms of cardiac contraction. What roles for preload, afterload and inotropic state in heart failure? Eur Heart $\mathcal{F}$ 1983; 4 (suppl A): 19-28.

59 Motulsky HJ, Insel PA. Adrenergic receptors in man: direct identification, physiologic regulation, and clinical alterations. $N$ Engl f Med 1982; 307: 18-29.

60 Johnston GD. Alternatives to the digitalis glycosides for heart failure. $\operatorname{Br}$ Med $\mathcal{F} 1985$; 290: 803-4. 